\title{
REAL-TIME POWER MEASUREMENTS IN SMART BUILDING MONITORING SYSTEM
}

\author{
OMAR S. KAREEM* and. DR. AHMED K. AL-SULAIFANIE** \\ *Dept .of Medical Laboratory Technology, Shekhan Technical college of Health, \\ Unversity of Polytechnic Dohuk, , Kurdistan Region-Iraq \\ *** Dept. of Electrical and Computer Engineering, College of Engineering,University of Dohuk, Kurdistan Region-Iraq
}

\begin{abstract}
The concept of a smart building or a home automation system is often characterized by the ability to control and monitor various household appliances to provide improved convenience, energy efficiency and security. In this paper a smart building real-time power monitoring system is proposed. The system targeted at enhanced safety and user awareness about power consumption with reduced cost. The consumed power can be instantaneously measured. The system can be programmed such in the case increasing power consumption, and start to turn off some insignificant appliances. Consequently, power consumption is reduced down and the cost is reduced. The general-purpose microcontroller (Arduino) available in market with low price. An interpolation technique is proposed to reduce the time of data acquisition. The experimental power load measurements achieved by proposed system are compared in the Lab with the precision and commercial power meters. The comparison shows good results, and the typical time required to measure the real power load and power factor is $\mathbf{4 2 . 8} \mathbf{m s}$ for one cycle measurement with 192 samples of data acquisition. The maximum error in measurements are $6 \% \mathrm{~W}$ for real power and $4 \%$ for PF.
\end{abstract}

KEYWORDS: Home Automation System; ZigBee; Smart Node; Overload Protection; Power Consumption; Interpolation

\section{INTRODUCTION}

$I^{\prime}$ $n$ the last few years, there has been a growing demand for electricity on the part of industries, commercial establishments and residential dwellings with the use of different appliances. This raises a concern to many developed and developing nations with the demand in immediate increase of electricity. For saving the energy, a reduction just $5 \%$ of the world's energy consumption would save the equivalent of more than 10 million barrels of oil a day and supply enough energy to Mexico, Australia and the United Kingdom (Nader, 2011). Energy savings are a common issue of everyday life. As energy prices increase, devices that can reduce the energy consumption become commonplace. However, the efficiency of energy saving solution is directly proportional to the accuracy of the acquired quantities (voltage and current). The knowledge of these quantities is essential for successive processing and to gather the passing current and terminal voltage and to perform basic data processing (Krejcar \& Frischer, 2012).

A computerized system can perform interactions with objects in the physical world which is called cyber physical systems (CPS) (Lee, 2008). To implement a smart building monitoring system some issues should be taken into consideration. The major cost of constructing a smart building is CPS systems. Even in the case of a smart home that can be built with less expensive CPS systems, further people can afford to have it. Therefore, the cost is first issue of constructing a smart building, while integrating with cloud computing is the second issue because Cloud computing offers users many kind of services (Lin, 2013). Open source solution is one of feasible approaches to address these issues. An approach to build smart homes with emerging open source solutions is proposed in this paper. The core of the proposed open source system is Arduino platform and support many low cost shields. This will give low running design cost when compared with specific application design circuitry. A module based on the proposed approach is also presented (Klemenjak, Egarter, \& Elmenreich, 2014).

Moreover, Wireless Sensor Network (WSN) use for sensing and transmitting electricity data and remote monitoring and control of home appliances are available to users through the intelligent home gateway in order to provide real- 
time electricity consumption information to users (Huang, Hong-ChanChang, Cheng-ChungChen, \& Cheng-ChienKuo, 2011) (Kim, Lee, \& Hwang, 2011). A ZigBee system is interoperable among manufacturers and supports a large number of nodes. The system provides connectivity among various electronic devices as well as an interactive and graphical interface to control these devices. ZigBee communication technology is designed to bring comfort and ease into peoples' lives, especially those of the elderly and disabled. The ZigBee protocol uses a radio frequency (RF) communication standard based on IEEE 802.15.4 (Nayan, Ikhsan, \& Takahashi, 2014). To support the remote control, it has developed different types of gateway for the integration of various communication interfaces such as, Global System for Mobile Communication (GSM). The system enables users to save energy by monitoring and controlling home appliances through measuring the power parameters.

The outline of the paper is as follows; in the section II a system overview is given. In section
III present a designed and implementation of proposed system, followed by the results and discussion in section IV. Finally, in section V the conclusions are presented.

\section{SMART BUILDING MONITORING SYSTEM OVERVIEW}

The monitoring and controlling system is proposed to provide a protection strategy on the basis of the wireless communication system. A smart node measures the parameters such as voltage, current, temperature, and power. These parameters are transmitted to a central node in order to provide real-time information of the outlet. The central node is calculated the power consumption of different branch according to the data received from the smart nodes, see Figure 1. The communication between the smart and the central node is a wireless network, for remote monitoring and controlling, the central node is contacted with GSM cellular network via a GSM shield (Ghazal, Akmal, Iyanna, \& Ghoudi, 2016) (Quan-Xi \& Gang, 2010).

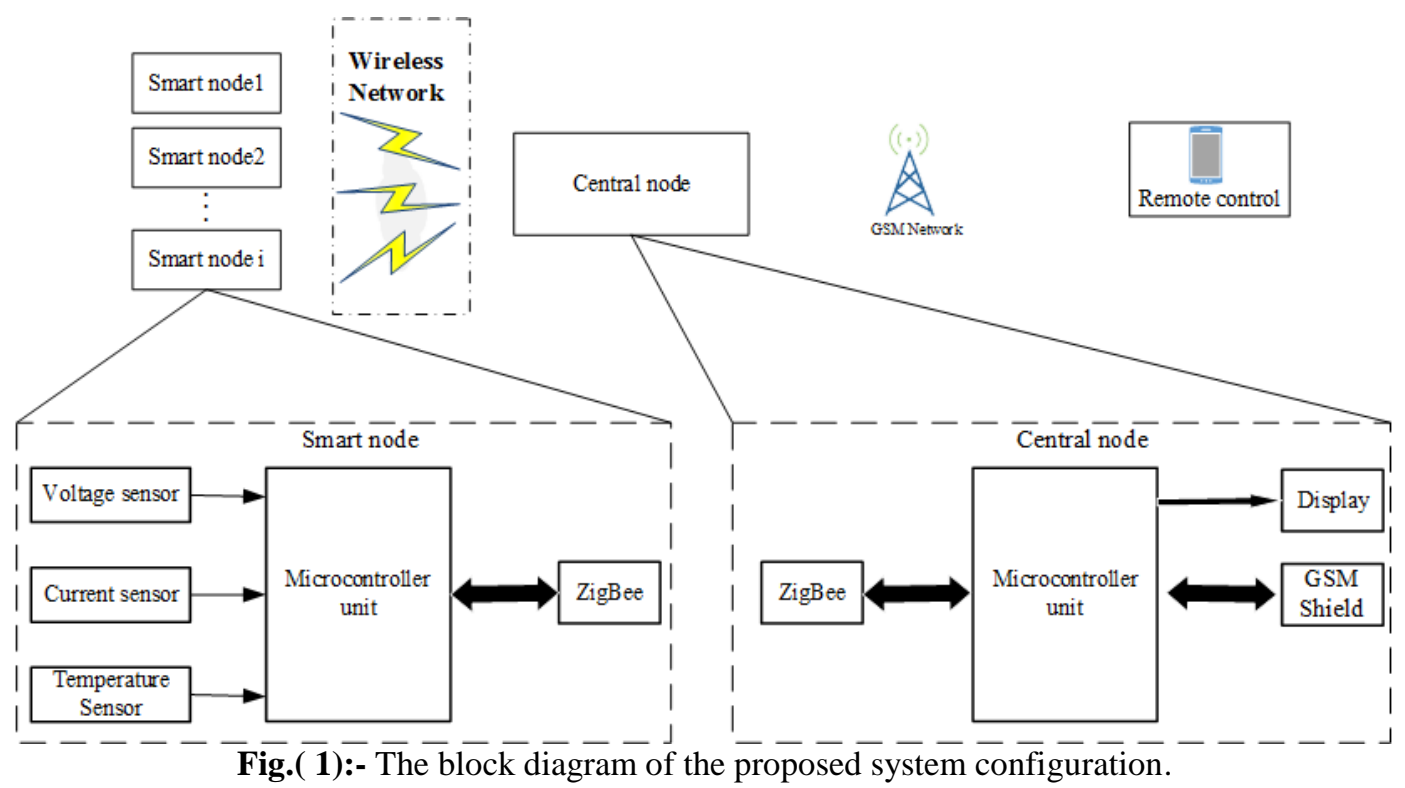

There are two integrate controllers used in the system, one for central node and another for smart nodes. The first one is for monitoring the smart nodes connected as WSN. As well it is used for external communication between household appliances and GSM network and displaying the values of power consumed by each smart node. The second controller used in the smart nodes to measure parameters. This node is intelligent and control any increase in the power above the normal range. The smart node also measuring temperature of electrical socket to avoid fire. The GSM shield, SIM900 GPRS/GSM as been used as the mediator between the microcontroller unit in central node and the mobile station and is responsible for the communication with the GSM network and sending/receiving phone text messages to turn on/off household appliances. 


\section{SYSTEM DESIGN}

This section described the proposed system structure which offers a safety mechanism of the power consumption in the buildings. The impact of sampling frequency on the accuracy of real power measurement is investigated to select the proper sampling frequency Fs for gathering the data. The increasing of sampling frequency requires abundance operations in calculations that are not necessary. Therefore, estimation of the suitable sampling frequency $F_{s}$ for system is significant. The effect and cost of the number of bits in ADC on measurement accuracy are also taken into account.

\subsection{Implementation of smart node}

The smart node, which is the measure and control node, is shown in Figure 2. The smart node hardware includes a power supply module, microcontroller section, power measurement module includes voltage sensor and current sensor, control module, temperature sensing module, indicator LEDs and a ZigBee module. The voltage and current sensor are the part that interfaces to the AC voltage lines. It converts $\mathrm{AC}$ voltages and currents to voltages sufficiently small to be measured directly by the ADC (Analog/Digital Converter) of the microcontroller. The ADC samples the analog input voltage, current signals and converts into digital form. The digital samples are given to $\mathrm{MCU}$ for calculating power. The operation of smart node is explained by the flowchart given in Figure 3.

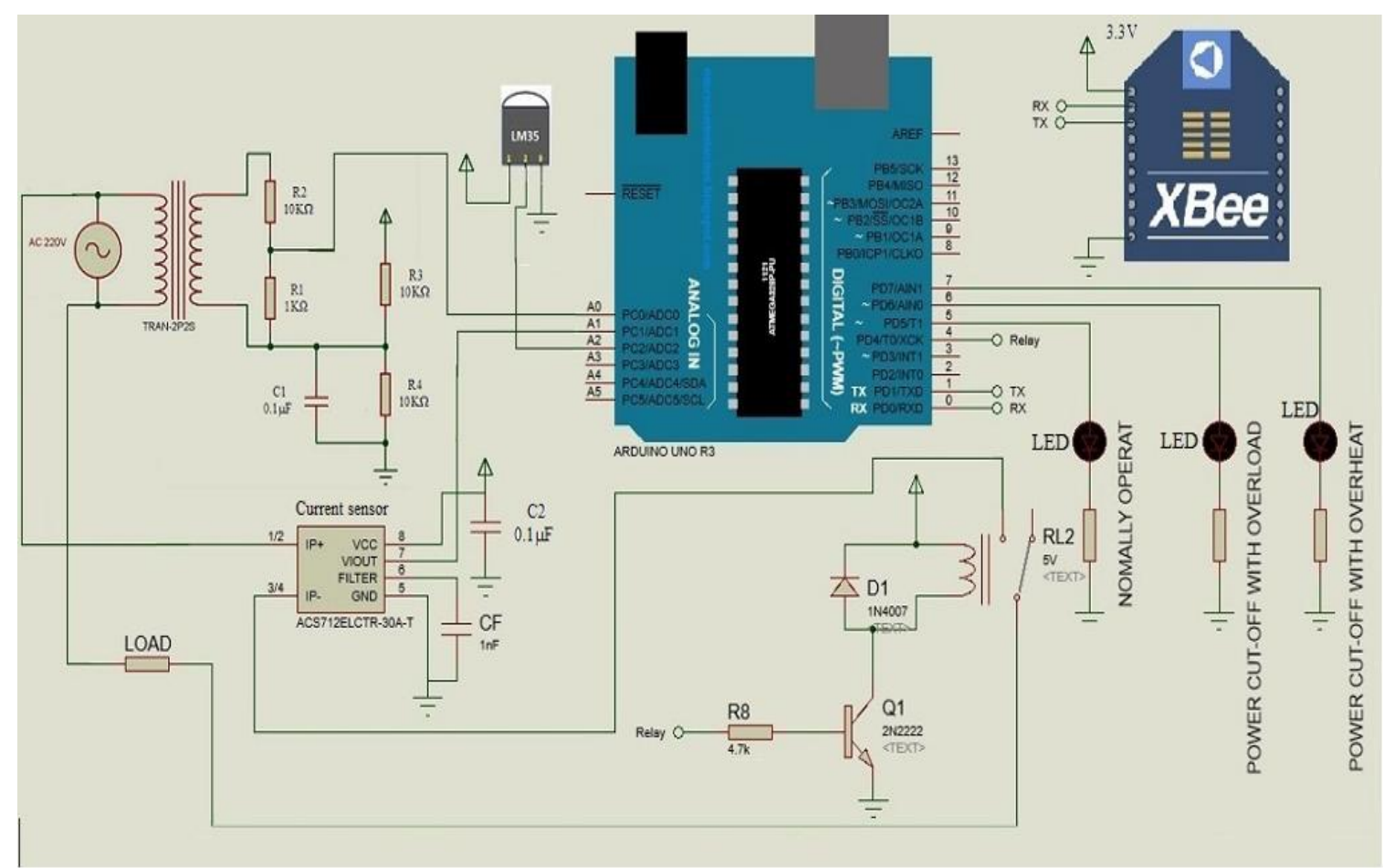

Fig.(2):- Implementation of smart node. 


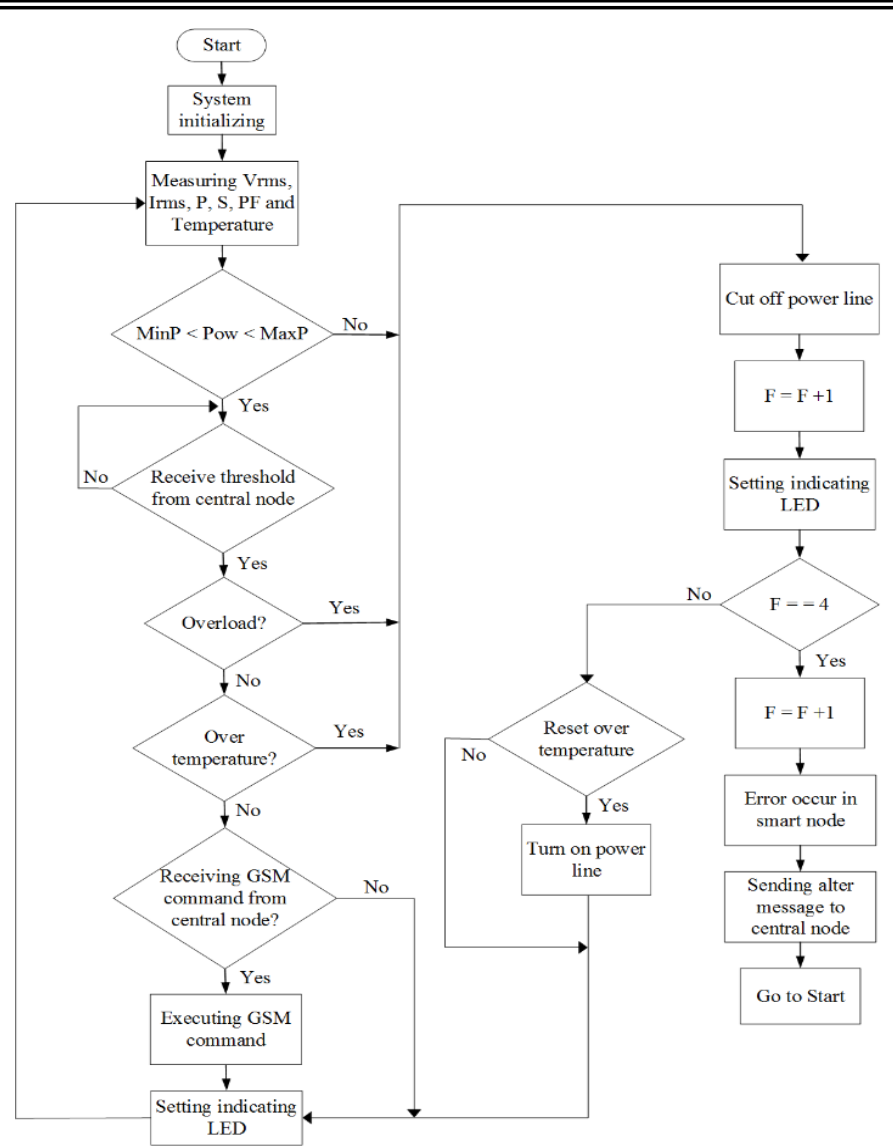

Fig. (3): -Flowchart of the smart node.

3.2 Sampling frequency Fs for gathering the data

Digital power meters have two inputs voltage and current signals. Measuring and analyzing the voltage and current provide the basis for all other values calculated in a digital power meter. Before analyzing voltage and current signals in a digital power metering device. The sampling process of the voltage and current analog signals should be taken at sufficient rate is crucial to ensure no losses of relevant event data occurred on the electrical system. However, as show in Figure 4 the measured values of voltage and current signals are multiplexed in time because of Atmega328P has only single ADC. The sampling frequency of Atmega328P is $9.6 \mathrm{KHz}$ but due to using the Fs for two signals reduce to the half $4.8 \mathrm{KHz}$ for each signal, as seen in Figure 4. The sampling time became $2 \mathrm{~T}_{\mathrm{s}}$ Therefore, each sample $\mathrm{I}(\mathrm{k})$ taken from current signal has a missed sample $\mathrm{V}(\mathrm{k})$ from voltage signal.

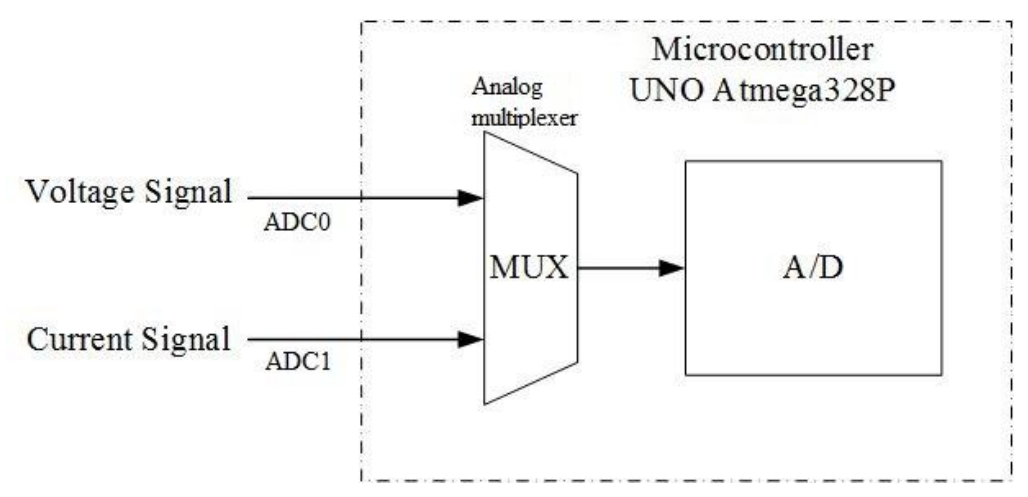

Fig.( 4):- Sampling two signals using single ADC. 
The timing diagram for the voltage and current gathering samples using multiplexed ADC is

shown in Figure 5.

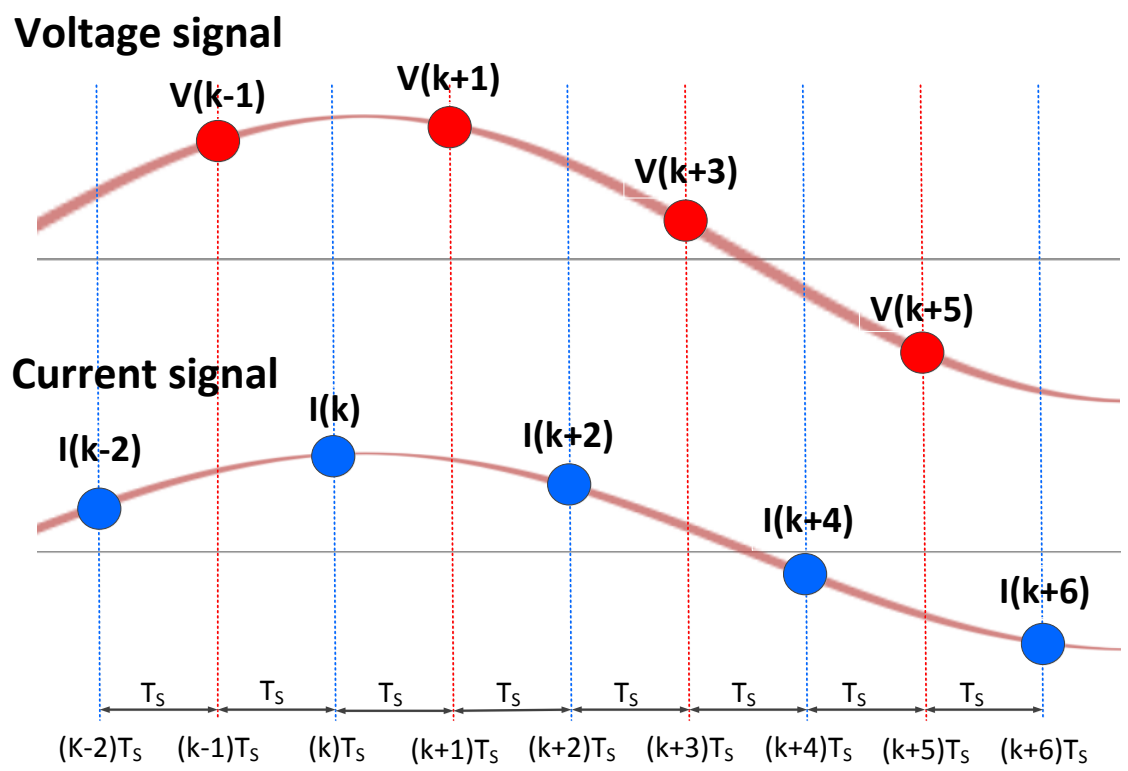

Fig.(5):- Voltage and Current gathering samples using multiplexed ADC.

To generate the missed voltage sample $\mathrm{V}(\mathrm{k})$ corresponding to the current sample signal $\mathrm{I}(\mathrm{k})$ at sampling time $\mathrm{kT}_{\mathrm{s}}$, the linear interpolation process is utilized by software. The computed interpolated voltage $\mathrm{V}(\mathrm{k})$ at sample time $\mathrm{kTs}$, at corresponding current sample $\mathrm{I}(\mathrm{k})$ are the approximate values of the missed voltage samples. The approximation of the missed value $\mathrm{V}(\mathrm{k})$ at sampling time $\mathrm{kT}_{\mathrm{s}}$ can be estimated from the two known pre and post voltage samples. The pre and post voltage samples are taken at sampling intervals (k-1)Ts and $(\mathrm{k}+1) \mathrm{Ts}$ of sampling voltage values $\mathrm{V}(\mathrm{k}-1)$ and $\mathrm{V}(\mathrm{k}+1)$ respectively. The linear interpolation is used to estimate $\mathrm{V}(\mathrm{k})$ between these two samples as the straight line. Since the sampling process is uniform then the missed sample value $\mathrm{V}(\mathrm{k})$ is the average between the pre and post samples, and given by (Vaseghi, 2000):

$\mathrm{V}(\mathrm{k})=\frac{\mathrm{V}_{\mathrm{k}+1}+\mathrm{V}_{\mathrm{k}-1}}{2}$

In the same manner the missed current sample $\mathrm{I}(\mathrm{k}+1)$ is estimated by

$\mathrm{I}(\mathrm{k}+1)=\frac{\mathrm{I}_{\mathrm{k}}+\mathrm{I}_{\mathrm{k}+2}}{2}$
The sampling frequency is $4.8 \mathrm{KHz}$ for each signal or $\mathrm{T}_{\mathrm{s}}=0.2083 \mathrm{~ms}$. Therefor the number of samples gathered in $20 \mathrm{~ms}$ (period of one cycle) is 96 samples. To re-sampling frequency to the former $9.6 \mathrm{KHz}$, the process of expanding can be utilized for the voltage and current discrete signals. This expanding process is done by inserting the zero values in odd index of the memory. Then the linear interpolation with expanding method is used to find the missed values, as shown in Figure 6.

In this work a three techniques are used in computation:

1. Computation without interpolation at $4.8 \mathrm{KHz}$ sampling rate by one sample delay between voltage and current samples.

2. Computation with interpolation at $4.8 \mathrm{KHz}$ sampling rate by evaluate the missed voltage samples corresponding to current samples.

3. Computation with interpolation at $9.6 \mathrm{KHz}$ sampling rate by expanding the missed corresponding of both voltage and current samples. 


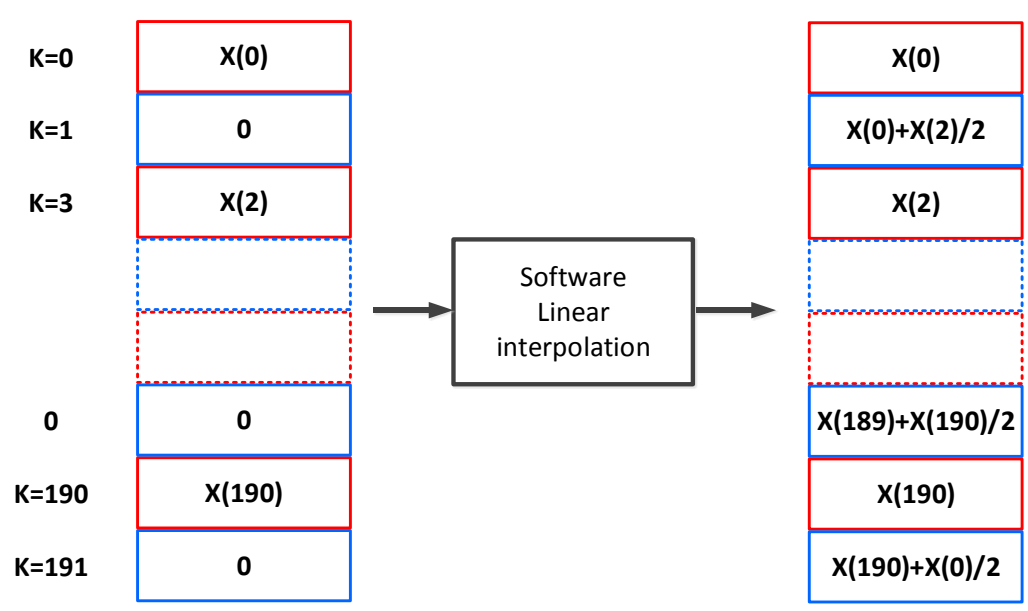

Fi.g( 6):- Resampling frequency to $9.6 \mathrm{KHz}$ using linear interpolation expanding.

\section{EXPERIMENTAL RESULTS and DISCUSSION \\ 4.1 Measurement Standards}

In order to calculate the real, reactive, apparent power, power factor, $\mathrm{V}_{\mathrm{rms}}$ and $\mathrm{I}_{\mathrm{rms}}$ using 10-bit quantized discrete sample values from the instantaneous analog voltage and current lines. The average real power is the accumulation of discrete time $V(n)$ and $I(n)$ samples product over a given time, and then divide by the number of samples $(\mathrm{N})$.

The discrete time equivalent is:

$$
\mathrm{P}=\frac{1}{\mathrm{~N}} \sum_{\mathrm{n}=0}^{\mathrm{N}-1} \mathrm{~V}(\mathrm{k}) \mathrm{I}(\mathrm{k})
$$

The RMS value is the square root of the arithmetic mean of the squares of the instantaneous values, for one cycle. The discrete time equation for calculating $\mathrm{V}_{\mathrm{rms}}$ as follows:

$$
\mathrm{V}_{\mathrm{rms}}=\sqrt{\frac{\sum_{\mathrm{n}=0}^{\mathrm{N}-1} \mathrm{~V}(\mathrm{k})^{2}}{\mathrm{~N}}}
$$

While $\mathrm{I}_{\mathrm{rms}}$ is calculated using the equation:

$$
I_{\mathrm{rms}}=\sqrt{\frac{\sum_{\mathrm{n}=0}^{\mathrm{N}-1} \mathrm{I}(\mathrm{k})^{2}}{\mathrm{~N}}}
$$

\subsection{Benchmarks measuring set up scheme}

For each load the theoretically and practical results are compared to verify the proposed system outcomes. The measured results included voltage, current, active, apparent and reactive power as well as the power factor. A set up scheme as show in Figure 7 is used for comparisons the measurement results of proposed system with two measuring benchmark instruments. The first is an international watt meter P3 model P4400.01 (Company p. , 2015), and the other analog-digital multi-meter SO5127$1 \mathrm{Z}$ from company Lucas Nuelle (Company 1.-n. , 2015). The result accuracy measurements are within $0.2 \%$ when compared with watt meter P3. While measurement accuracy of $2 \%$ is established compared with analog-digital multi-meter SO5127-1Z from company Lucas Nuelle 


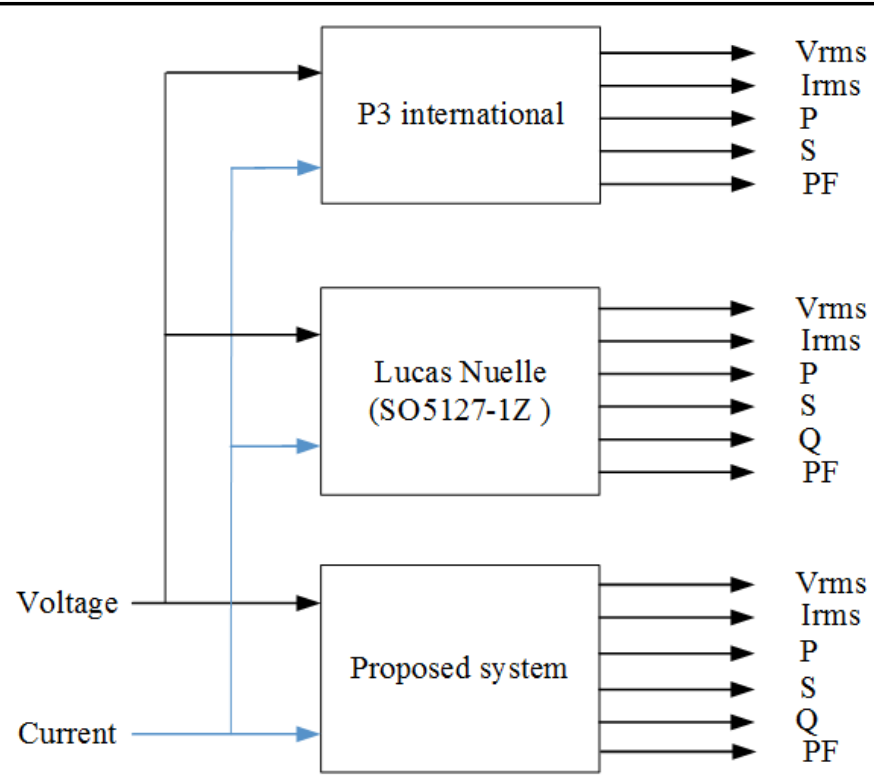

Fig. (7):- Parameters measure by all devices.

\subsection{Experimental results}

In order to verify the operation of the proposed system, a real physical loads are employed to measure $\mathrm{V}_{\mathrm{rms}}, \mathrm{I}_{\mathrm{rms}}$, apparent and reactive power, and PF. A four cases of loads, in all cases the voltage rating power line is $220 \mathrm{~V}$, the sampling frequency $F_{s}$ is $9.6 \mathrm{KHz}$ and the $\mathrm{ADC}$ word length of sampled data is 10-bits, also there are three cases for actual loads.

Case 1: Resistive $150 \Omega$ load.
As shown in the table 1, the experimental results measured by proposed system are obtained using three manipulation techniques: without interpolation, interpolation and interpolation with expanding. Each case has two values Min and Max. Min represents the lowest value and Max represents the highest value that has been reading. In addition, error percentage has been calculate between the proposed system and Lucas-Nuelle as note in the last column of the table 1.

Table (1):- Compare results for resistive load.

\begin{tabular}{|c|c|c|c|c|c|c|c|c|c|c|}
\hline \multirow{3}{*}{$\begin{array}{c}\text { Paramete } \\
\text { rs }\end{array}$} & \multirow{3}{*}{$\begin{array}{c}\text { Theor } \\
\mathbf{y}\end{array}$} & \multirow{3}{*}{$\begin{array}{c}\text { P3 } \\
\text { international }\end{array}$} & \multirow{3}{*}{$\begin{array}{c}\text { Lucas- } \\
\text { Nuelle } \\
\text { S05127- } \\
1 Z\end{array}$} & \multicolumn{6}{|c|}{ Proposed system } & \multirow{3}{*}{$\begin{array}{l}\text { \%MAX } \\
\text { Error }\end{array}$} \\
\hline & & & & \multicolumn{2}{|c|}{$\begin{array}{c}\text { Without } \\
\text { Interpolation }\end{array}$} & \multicolumn{2}{|c|}{ Interpolation } & \multicolumn{2}{|c|}{$\begin{array}{l}\text { Interpolation } \\
\text { with expand }\end{array}$} & \\
\hline & & & & Min & Max & Min & Max & Min & Max & \\
\hline $\mathrm{V}_{\text {rms }}(\mathrm{V})$ & 220 & 217 & 218 & 215.06 & 217.21 & 214.89 & 217.07 & 214.81 & 217.00 & $0.45 \%$ \\
\hline $\mathrm{I}_{\mathrm{rms}}(\mathrm{A})$ & 1.46 & 1.47 & 1.45 & 1.45 & 1.47 & 1.45 & 1.47 & 1.45 & 1.47 & $1.37 \%$ \\
\hline $\mathrm{P}(\mathrm{W})$ & 319 & 321 & 324 & 309.87 & 316.85 & 309.59 & 316.64 & 309.37 & 316.42 & $2.33 \%$ \\
\hline $\mathrm{S}(\mathrm{VA})$ & 319 & 322 & 325 & 311.20 & 318.38 & 310.95 & 318.18 & 310.68 & 317.91 & $2.18 \%$ \\
\hline $\mathrm{Q}$ (VAR) & 0 & - & 25 & 28.68 & 31.15 & 29.04 & 31.27 & 28.53 & 30.73 & $22.9 \%$ \\
\hline PF & 1.00 & 1.00 & 1.00 & 1.00 & 1.00 & 1.00 & 1.00 & 1.00 & 1.00 & $0 \%$ \\
\hline
\end{tabular}

Case( 2):- the load contains resistance and inductance $\mathrm{R}=75 \Omega$ and $\mathrm{L}=610 \mathrm{mH}$.

In the inductive loads, the current lags voltage according to the value of inductance, whenever it increases the phase angle between voltage and current become bigger and power factor decrease. When using interpolation process the PF value become close the theoretical value, which means reducing the shift between voltage and current which causes by single ADC. Last column in table 2 shows percentage error between proposed system and Lucas-Nuelle. 
Table (2 ):-Compare results for resistive and inductive load.

\begin{tabular}{|c|c|c|c|c|c|c|c|c|c|c|}
\hline \multirow{3}{*}{$\begin{array}{l}\text { Paramete } \\
\text { rs }\end{array}$} & \multirow{3}{*}{$\begin{array}{l}\text { Theor } \\
\text { y }\end{array}$} & \multirow{3}{*}{$\begin{array}{l}\text { P3 } \\
\text { international }\end{array}$} & \multirow{3}{*}{$\begin{array}{l}\text { Lucas- } \\
\text { Nuelle } \\
\text { SO5127- } \\
1 Z\end{array}$} & \multicolumn{6}{|c|}{ Proposed system } & \multirow{3}{*}{$\begin{array}{l}\% \\
\text { Error }\end{array}$} \\
\hline & & & & \multicolumn{2}{|c|}{$\begin{array}{c}\text { Without } \\
\text { Interpolation }\end{array}$} & \multicolumn{2}{|c|}{ Interpolation } & \multicolumn{2}{|c|}{$\begin{array}{l}\text { Interpolation } \\
\text { with expand }\end{array}$} & \\
\hline & & & & Min & Max & Min & $\operatorname{Max}$ & Min & Max & \\
\hline $\mathrm{V}_{\mathrm{rms}}(\mathrm{V})$ & 220 & 216 & 217 & 218.71 & 217.49 & 218.58 & 217.28 & 218.51 & 217.19 & $0.087 \%$ \\
\hline$I_{\text {rms }}(A)$ & 1.07 & 0.90 & 0.91 & 0.90 & 0.93 & 0.90 & 0.93 & 0.90 & 0.93 & $2.19 \%$ \\
\hline $\mathrm{P}(\mathrm{W})$ & 85 & 81 & 79 & 77.1 & 82.53 & 70.45 & 75.71 & 70.47 & 75.74 & $4.12 \%$ \\
\hline S (VA) & 234 & 202 & 196 & 197.04 & 201.68 & 196.92 & 201.48 & 196.74 & 201.33 & $2.72 \%$ \\
\hline Q (VAR) & 218 & - & 179 & 181.32 & 184.02 & 183.89 & 186.72 & 183.69 & 186.54 & $4.21 \%$ \\
\hline PF & 0.365 & 0.40 & 0.39 & 0.39 & 0.41 & 0.36 & 0.38 & 0.36 & 0.38 & $2.56 \%$ \\
\hline
\end{tabular}

Case 3: the load contains resistance and capacitance $\mathrm{R}=140 \Omega$ and $\mathrm{C}=12 \mu \mathrm{F}$.

In the capacitive loads, the current leads voltage as result using single $\mathrm{ADC}$ the phase between the voltage and current reduce by one sample. So the Pf value become well than the theoretical value, but after using interpolation process the value become closer to the theoretical value. Last column in table 3 shows percentage error between proposed system and Lucas-Nuelle is more than error in the table 2 .

Table (3 ):-Compare results for resistive and capacitive load.

\begin{tabular}{|c|c|c|c|c|c|c|c|c|c|c|}
\hline \multirow{3}{*}{$\begin{array}{l}\text { Paramete } \\
\text { rs }\end{array}$} & \multirow[t]{3}{*}{ Theory } & \multirow{3}{*}{$\begin{array}{c}\mathbf{P 3} \\
\text { internatio } \\
\text { nal }\end{array}$} & \multirow{3}{*}{$\begin{array}{c}\text { Lucas- } \\
\text { Nuelle } \\
\text { so5127-1Z }\end{array}$} & \multicolumn{6}{|c|}{ Proposed system } & \multirow{3}{*}{$\begin{array}{l}\text { \% MAX } \\
\text { Error }\end{array}$} \\
\hline & & & & \multicolumn{2}{|c|}{$\begin{array}{c}\text { Without } \\
\text { Interpolation }\end{array}$} & \multicolumn{2}{|c|}{ Interpolation } & \multicolumn{2}{|c|}{$\begin{array}{l}\text { Interpolation } \\
\text { with expand }\end{array}$} & \\
\hline & & & & Min & Max & Min & Max & Min & $\operatorname{Max}$ & \\
\hline $\mathrm{V}_{\mathrm{rms}}(\mathrm{V})$ & 220 & 219 & 222 & 223.35 & 223.84 & 223.17 & 223.80 & 223.09 & 223.74 & $0.78 \%$ \\
\hline$I_{\text {rms }}(A)$ & 0.75 & 0.72 & 0.73 & 0.76 & 0.77 & 0.76 & 0.77 & 0.90 & 0.77 & $5.47 \%$ \\
\hline $\mathrm{P}(\mathrm{W})$ & 78 & 68 & 73 & 72.91 & 78.29 & 78.46 & 83.85 & 78.48 & 83.77 & $14.75 \%$ \\
\hline S (VA) & 168 & 157 & 159 & 168.64 & 172.83 & 168.50 & 172.80 & 168.31 & 172.53 & $8.5 \%$ \\
\hline $\mathrm{Q}$ (VAR) & -150 & - & -141 & $\begin{array}{c}- \\
152.06\end{array}$ & $\begin{array}{c}- \\
154.08\end{array}$ & $\begin{array}{c}- \\
149.12\end{array}$ & $\begin{array}{c}- \\
151.09\end{array}$ & $\begin{array}{c}- \\
148.92\end{array}$ & $\begin{array}{c}- \\
150.83\end{array}$ & $6.97 \%$ \\
\hline $\mathrm{PF}$ & 0.467 & 0.43 & 0.455 & 0.42 & 0.45 & 0.47 & 0.49 & 0.47 & 0.49 & $7.69 \%$ \\
\hline
\end{tabular}

Case 4: the load contains on resistance, inductance and capacitance $\mathrm{R}=140 \Omega, \mathrm{L}=$ $610 \mathrm{mH}$ and $\mathrm{C}=12 \mu \mathrm{F}$.

In this case the load is capacitive, when the interpolation process is used the PF value become close to the theoretical value. The real power also become closer to theoretical, which means obtain on better result when used interpolation.

Table( 4):- Compare results for resistive, inductive and capacitive load.

\begin{tabular}{|c|c|c|c|c|c|c|c|c|c|c|}
\hline \multirow{3}{*}{$\begin{array}{l}\text { Parame } \\
\text { ters }\end{array}$} & \multirow[t]{3}{*}{ Theory } & \multirow{3}{*}{$\begin{array}{c}\text { P3 } \\
\text { international }\end{array}$} & \multirow{3}{*}{$\begin{array}{c}\text { Lucas- } \\
\text { Nuelle } \\
\text { S05127-1Z }\end{array}$} & \multicolumn{6}{|c|}{ Proposed system } & \multirow{3}{*}{$\begin{array}{c}\text { \% MAX } \\
\text { Error }\end{array}$} \\
\hline & & & & \multicolumn{2}{|c|}{$\begin{array}{c}\text { Without } \\
\text { Interpolation }\end{array}$} & \multicolumn{2}{|c|}{ Interpolation } & \multicolumn{2}{|c|}{$\begin{array}{l}\text { Interpolation } \\
\text { with expand }\end{array}$} & \\
\hline & & & & Min & Max & Min & $\operatorname{Max}$ & Min & Max & \\
\hline $\mathrm{V}_{\mathrm{rms}}(\mathrm{V})$ & 220 & 222 & 228 & 228.71 & 230.42 & 228.47 & 230.25 & 228.38 & 230.17 & $0.95 \%$ \\
\hline $\mathrm{I}_{\mathrm{rms}}(\mathrm{A})$ & 1.39 & 1.27 & 1.29 & 1.29 & 1.30 & 1.29 & 1.30 & 1.29 & 1.30 & $0.77 \%$ \\
\hline $\mathrm{P}(\mathrm{W})$ & 270 & 255 & 260 & 256.00 & 263.12 & 260.43 & 267.50 & 260.26 & 267.53 & $2.89 \%$ \\
\hline $\mathrm{S}(\mathrm{VA})$ & 305 & 282 & 290 & 294.09 & 299.86 & 293.78 & 299.64 & 293.51 & 299.33 & $3.21 \%$ \\
\hline Q (VAR) & -143 & - & -130 & $\begin{array}{c}- \\
144.74\end{array}$ & $\begin{array}{c}- \\
143.83\end{array}$ & $\begin{array}{c}- \\
135.95\end{array}$ & $\begin{array}{c}- \\
134.88\end{array}$ & $\begin{array}{c}- \\
135.69\end{array}$ & $\begin{array}{c}- \\
134.61\end{array}$ & $3.54 \%$ \\
\hline PF & 0.88 & 0.90 & 0.89 & 0.87 & 0.88 & 0.89 & 0.89 & 0.89 & 0.89 & $0 \%$ \\
\hline
\end{tabular}

In addition to pervious loads which used in order to determine efficiency of the proposed system in measuring power at different cases and compared with it theory values. Actual loads will 
be used such as lamp, refrigerator and air cooler and comparison the measurement results of proposed system just with instrument international watt meter P3.

Case 5: lamp 500W load.

In this case the lamp is not a $100 \%$ resistive load so there is a slight difference between real and apparent power. Also the power factor will be between 0.99-1.0 as shown in table 5. The maximum error percentage has been calculating between the proposed system and international P3 as note in the last column of the table 5 .

Table( 5):- Compare results for lamp load.

\begin{tabular}{llccc}
\hline Parameters & P3 & \multicolumn{2}{c}{ Proposed system } & \multirow{2}{*}{ \% MAX Error } \\
\cline { 2 - 4 } & international & Min & Max & \\
\cline { 2 - 4 } & & 212.9 & 215.6 & $0.41 \%$ \\
\hline $\mathrm{V}_{\text {rms }}(\mathrm{V})$ & 214.7 & 2.26 & 2.29 & $0.88 \%$ \\
\hline $\mathrm{I}_{\text {rms }}(\mathrm{A})$ & 2.27 & 485.53 & 491.85 & $1.06 \%$ \\
\hline $\mathrm{P}(\mathrm{W})$ & 486.67 & 484.34 & 492.77 & $0.96 \%$ \\
\hline $\mathrm{S}(\mathrm{VA})$ & 488.08 & 0.99 & 1.0 & $0 \%$ \\
\hline $\mathrm{PF}$ & $0.99-1.0$ & & &
\end{tabular}

Case 6: refrigerator load.

In the case of refrigerator load is made up of resistance, induction and capacitor. The results of the proposed system and P3 are close as shown in the table 6 .

Table 6 ):-Compare results for refrigerator load.

\begin{tabular}{ccccc}
\hline Parameters & $\begin{array}{c}\text { P3 } \\
\text { international }\end{array}$ & \multicolumn{2}{c}{ Proposed system } & \multirow{2}{*}{ \% MAX Error } \\
\cline { 3 - 4 } & & Min & Max & \\
\hline $\mathrm{V}_{\mathrm{rms}}(\mathrm{V})$ & 218.8 & 218.53 & 221.52 & $1.2 \%$ \\
\hline $\mathrm{I}_{\mathrm{mms}}(\mathrm{A})$ & 1.14 & 1.12 & 1.16 & $1.7 \%$ \\
\hline $\mathrm{P}(\mathrm{W})$ & 135 & 133.87 & 138.07 & $2.2 \%$ \\
\hline $\mathrm{S}(\mathrm{VA})$ & 250 & 248.91 & 256.47 & $2.5 \%$ \\
\hline $\mathrm{PF}$ & 0.54 & 0.53 & 0.56 & $3.7 \%$ \\
\hline
\end{tabular}

Case 7: air cooler load.

In this case the load is air cooler, also the load is made up of resistance, induction and capacitor.
The results of the proposed system and P3 are close and error percentage is smaller as shown in the table 7.

Table( 7):- Compare results for air cooler load.

\begin{tabular}{ccccc}
\hline \multirow{2}{*}{$\begin{array}{c}\text { Paramete } \\
\text { rs }\end{array}$} & $\begin{array}{c}\text { P3 } \\
\text { international }\end{array}$ & \multicolumn{2}{c}{ Proposed system } & \% MAX Error \\
\cline { 3 - 4 } & & Min & Max & \\
\hline $\mathrm{V}_{\text {rms }}(\mathrm{V})$ & 215.43 & 217.31 & 218.52 & $1.4 \%$ \\
\hline $\mathrm{I}_{\text {rms }}(\mathrm{A})$ & 1.71 & 1.72 & 1.75 & $2.3 \%$ \\
\hline $\mathrm{P}(\mathrm{W})$ & 278 & 277 & 282.13 & $1.4 \%$ \\
\hline $\mathrm{S}(\mathrm{VA})$ & 380 & 379.78 & 384.93 & $1.2 \%$ \\
\hline $\mathrm{PF}$ & 0.73 & 0.72 & 0.74 & $1.3 \%$ \\
\hline
\end{tabular}

After measuring parameters of the previous loads the time required is calculated, to calculate each parameter, as show in table 8, after $42800 \mu \mathrm{s}$ can calculate the power factor. The total time required for real power calculation is $42.8 \mathrm{~ms}$ and the time require to do interpolation process is 4.58 $\mathrm{ms}$, with the observation this time is for one cycles and 170 samples. Total time required to store all samples of both signal in memory require 27400 $\mu \mathrm{s}$, see table 8 . 
Table( 8):- Required time for calculation each parameter.

\begin{tabular}{cc}
\hline Parameters & Required time for calculation \\
\hline $\mathrm{P}$ & $42564 \mu \mathrm{s}$ \\
\hline $\mathrm{V}_{\mathrm{rms}}$ & $42620 \mu \mathrm{s}$ \\
\hline $\mathrm{I}_{\mathrm{rms}}$ & $42668 \mu \mathrm{s}$ \\
\hline $\mathrm{S}$ & $42680 \mu \mathrm{s}$ \\
\hline $\mathrm{Q}$ & $42764 \mu \mathrm{s}$ \\
\hline $\mathrm{PF}$ & $42800 \mu \mathrm{s}$
\end{tabular}

\section{CONCLUSION}

Power monitor is the most effective method for power saving and safety protection, combined with ZigBee for wireless transmission. The ZigBee offers convenience for remote monitoring of the status of plug point. The feature of ZigBee in supporting to a large number of nodes is benefit for its future expansion where the newly migrated intelligent outlet nodes could combine with the original system immediately. The system is controlled by sending SMS messages to central node, the mobile phone does not require any special hardware or application to be used as a mobile station. The smart node uses to measure parameters e.g. Vrms, Irms and real power. The interpolation process is used the real power is improved to real value theoretical. The results of real is improved when implementation the proposed system, see tables 1-4 There are some difference between results not near to theoretical results, because error percentage of loads. Also Actual loads has been measured from home, when the results are compared, they were close as shown in tables 5-7. The required time for store the samples of voltage and current signals is around $27.4 \mathrm{~ms}$. The total time required for calculate the real power and power factor is $42.8 \mathrm{~ms}$ for one cycle. So, when comparing the results with another power meters $\mathrm{P} 3$ international and analog-digital multimeter SO5127-1Z the results is very near to what may measuring by proposed system for all loads.

\section{REFERENCES}

Company, 1.-n. (2015, December 15). Retrieved from Lucas-Nülle GmbH: https://www.lucasnuelle.com/1004/pid/13196/apg/7019/Analogdigital-multimeter,-wattmeter-+-power-factormeter-inclAe-software.htm.

Company, p. (2015, December 10). P3 International Corporation. Retrieved from P3International: http://www.p3international.com/products/p4400 .html

Ghazal, M., Akmal, M., Iyanna, S., \& Ghoudi, K. (2016). Smart plugs: Perceived usefulness and satisfaction: Evidence from United Arab Emirates. Elsevier Renewable \& Sustainable Energy Reviews, 1248-1259.

Huang, L.-C., Hong-ChanChang, Cheng-ChungChen, \& Cheng-ChienKuo. (2011). A ZigBee-based monitoring and protection system for building electrical safety. Elsevier Energy and Buildings, $1418-1426$

Kim, W. H., Lee, S., \& Hwang, J. (2011). Real-time Energy Monitoring and Controlling System based on ZigBee Sensor Networks. International Symposium on Intelligent Systems Techniques for Ad hoc and Wireless Sensor Networks (IST-AWSN), 794-797.

Klemenjak, C., Egarter, D., \& Elmenreich, W. (2014). YoMo - The Arduino-based Smart Metering Board. Institute of Networked and Embedded Systems, 97-103.

Krejcar, O., \& Frischer, R. (2012). Real Time Voltage and Current Phase Shift Analyzer for Power Saving Applications. sensors, 11391-11405.

Lee, E. A. (2008). Cyber Physical Systems: Design Challenges. International Symposium on Object/Component/Service-Oriented Real-Time Distributed Computing (ISORC), 363-369.

Lin, H.-T. (2013). Implementing Smart Homes with Open Source Solutions. International Journal of Smart Home, 289-296.

Nader, W. (2011). REAL-TIME POWER MONITORING, HOME AUTOMATION AND SUSTAINABILITY. (M.Sc Thesis). Unversity of Nebraska-Lincoln.

Nayan, N. A., Ikhsan, I. A., \& Takahashi, Y. (2014). Using ZigBee Communication Technology in a Smart Home Wireless Sensor Network. Proceedings of Second International Conference on Modern Trends in Science, Engineering and Technology, 19-25.

Quan-Xi, L., \& Gang, L. (2010). Design of remote automatic meter reading system based on ZigBee and GPRS. Proceedings of the Third International Symposium on Computer Science and Computational Technology(ISCSCT '10), 186-189.

Vaseghi, S. V. (2000). Advanced Digital Signal Processing and Noise Reduction, Second Edition. Chichester. New York: John Wiley \& Sons, Ltd. 